\title{
Study on Remediation of Hexachlorobenzene Contaminated Soil by Mechanochemical Method
}

\author{
Li Xue $^{1}$, Chen Huichao ${ }^{1, *}$, Liang Xiao ${ }^{1}$ \\ ${ }^{1}$ Southeast University, School of Energy and Environment, Nanjing, 210096, Jiangsu, China
}

\begin{abstract}
The mechanochemical method is a potential way to destroy pollutants such as heavy metals and organic compounds due to its advantages such as complete reaction, adaptation of various pollutants and low energy consumption, etc. Research work was conducted to investigate the feasibility of remediating the persistent organic pollutants (POPs) contaminated soil and how the parameters influence the destruction of the pollutants. In the study, hexachlorobenzene (HCB) was used as a presentative of the POPs in soil. Natural minerals such as albite and magnetite were selected as additives to treat HCB contaminated soil with the application of mechanochemical method. The reasonable operation parameters as well as the soil properties on the destruction of HCB were determined. Analysis such as Fourier Transform Infrared Spectroscopy (FTIR), X-ray diffractometer (XRD), X-ray Photoelectron Spectroscopy (XPS) and Raman Spectrometer were conducted for the supplement of mechanism study. A degradation rate of $92.5 \%$ for HCB was achieved under the optimal reaction condition. According to the XPS analysis results, the transformed valence state of iron, provided electrons for the destruction of $\mathrm{HCB}$, on the basis of specific structure of albite. The amorphous carbon and graphite carbon were the final products of the destruction of HCB in the process of ball milling. The selected reagents with albite and magnetite would be viable for the damage of other POPs by mechanochemical method.
\end{abstract}

\section{Introduction}

A wide range of industrial products, resulting in complex pollution components, including a variety of heavy metals and organic pollutants, and the toxicity of persistent organic pollutants (POPs) to organisms has aroused wide concern [1]. Since the implementation of the Stockholm Convention, the manufacture and application of many kinds of POPs products have been restricted. However, the problem of soil pollution caused by product circulation, production leakage and abandoned factory field is very serious [2-4], then the research of soil remediation has become a hot spot. Moreover, the rapid remediation technologies of soil contaminated by organic pollutants cover extensively, including chemical reduction oxidation $[5,6,7]$, soil leaching technology [8], photocatalytic degradation $[9,10,11]$, plasma photolysis and so on, with various requirements for the contaminated site. Physical methods, i.e., electro-kinetic remediation $[9,12,13,14]$, soil vapor extraction $[15,16]$, thermal desorption $[17,18,19]$, supercritical fluid extraction [20], etc., also display certain efficiency. It is necessary to restore the nature of soil after remediation. Apart from the mentioned applications, the biological treatments also work [21,22], in spite of long period of remediation time. Therefore, to explore soil remediation technologies with high efficiency and environment protection has become a top priority.

With the investigation of mechanochemistry, researches of applying ball mill as a reactor to treat solid waste get flourished, for the superiorities it preserves, i.e., no-combustion, possible implementation process, less release of byproducts with toxicity $[23,24]$, etc. The application of high efficient co-milling reagents can enhance the destruction reaction, shorten the repair time and realize the complete degradation of pollutants. Since Rowlands found that when $\mathrm{CaO}$ was used as the reagent, no original pollutants could be detected in the products of POPs, such as PCBs, chlorobenzene and DDTs by mechanical ball milling, and then $\mathrm{CaO}$ became the preferred co-milling reagent for mechanical and chemical degradation of POPs [25]. Many studies have been implemented with $\mathrm{CaO}$ as the main grinding assistant.

It was probed that, the PCBs contaminated soil was remediated by planetary ball mill with $\mathrm{CaO}$ and $\mathrm{SiO}_{2}$ as reagents, and found that the total amount and toxicity equivalent of PCBs were reduced by $74 \%$ and $78 \%$ respectively [26]. Since then, the investigation of additives on organic compounds decomposition has gradually covered alkali metal oxides, neutral substances, oxidants and some reducing agents [27]. For example, it was proved that $\mathrm{MgO}, \mathrm{Al}_{2} \mathrm{O}_{3}$ and $\mathrm{La}_{2} \mathrm{O}_{3}$ present great effect on the treatment of monochlorobiphenyl by ball milling [28]. As a neutral substance, $\mathrm{CaC}_{2}$ shows great advantages in the process of degradation of hexachlorobenzene on mechanochemical method [24].

The existing researches on mechanochemical

\footnotetext{
*Corresponding Author: hcchen@seu.edu.cn
} 
treatment of POPs contaminated soil showed that exogenous additives applied present impact on soil texture, although they are efficient in the removal of pollutants. For example, the addition of $\mathrm{CaO}$ results in the increase of soil alkalinity, inhibits plant growth and has adverse effects on soil reclamation. Therefore, it is of great significance to explore the degradation of POPs contaminated soil by mechanochemistry with natural minerals which are similar to soil components and rich in source, to efficiently and economically remediate POPs contaminated field with full utilization of occupied field resources.

Albite belongs to feldspar group minerals, one of the sources of soil minerals with rich reserves and diverse compositions, such as $\mathrm{Al}_{2} \mathrm{O}_{3}, \mathrm{SiO}_{2}$ and so on, which also has developed pore structure. And it is expected to realize the efficient degradation of pollutants by combing with magnetite, potential to provide internal electron transfer during the mechanochemistry process. In the study, natural mineral combination was used as co-milling reagents, with albite as main grinding agent and magnetite as grinding assistant, to study the mechanochemical effect on decomposition of hexachlorobenzene (HCB) in contaminated soil. The optimal parameters were determined, as well as the soil texture effect. And the mechanism of decomposition of HCB was studied with supplement of characterized methods.

\section{Materials and method}

\subsection{Chemicals and instruments}

Hexachlorobenzene (HCB, purity: 99.6\%) was produced by Shenyang Research Institute of Chemical Industry (China), N-hexane (purity: pesticide analysis grade) was purchased from Nanjing Chemical Reagent Company Limited (China), Acetone (purity: pesticide analysis grade) was produced by Anhui Tiandi High Purity Solvent Company Limited (China), Albite (500 mesh) was produced by Yanxi mine (China), Fe3O4 (purity: 85\%) was purchased from Aladdin Reagent Company limited (China), Montmorillonite (500 mesh) was purchased from Huzhou Chengke New Material Corporation (China), Quartz sand (20-40 mesh) was purchased from Shanghai Taitan Corporation.

A planetary ball mill (F-P400E, FOCUCY, China) with four zirconia pots was used for mechanochemical degradation experiments, An ultrasonic microwave collaborative reaction workstation (XO-SM100, ATPIO, China) was applied to extract target pollutants, A low speed centrifuge (TDZ5-WS, XIANGZHI, China) was employed to separate solid particles from liquids, A Nitrogen blowing concentrator (WD-12, Allsheng, China) was used to concentrate the substance to be tested, A gas chromatography mass spectrometry (A91 PLUS, PANNA, China) was applied to test target pollutants.

\subsection{Materials}

Fresh garden soil was collected according to the multipoint mixed sampling method, crushed and mixed by hand, and reduced to about $1 \mathrm{~kg}$ by quartering method. Chemical analysis of soil samples showed that HCB was not detected. The properties of the soil samples such as total nitrogen $(\mathrm{TN}, \mathrm{g} / \mathrm{kg})$, total phosphorus $(\mathrm{TP}, \mathrm{g} / \mathrm{kg})$, total potassium (TK, g/kg), $\mathrm{pH}$, organic matter (OM, \%), electrical conductivity $(\mathrm{EC}, \mu \mathrm{s} / \mathrm{cm})$ and cation exchange capacity $(\mathrm{CEC}, \mathrm{cmol}(+) / \mathrm{kg})$, were detected and the results are shown in Table 1.

Table1. The properties of the tested soil

\begin{tabular}{cccccccc}
\hline $\mathbf{P}$ & $\mathrm{TN}$ & $\mathrm{TK}$ & $\mathrm{TP}$ & $\mathrm{pH}$ & $\mathrm{OM}$ & $\mathrm{EC}$ & $\mathrm{CEC}$ \\
\hline $\mathbf{C}$ & 1.63 & 22.9 & 1.15 & 7.28 & 3.09 & 284 & 18 \\
\hline
\end{tabular}

Where $\mathrm{P}$ is the abbreviation of parameters and $\mathrm{C}$ is the abbreviation of component contents.

\subsection{Experiments}

\subsubsection{Preparation of simulated contaminated soil}

The fresh soil sample was crushed and sieved through 100 mesh nylon sieve after air drying, and then put into an amber glass wide mouth packer. The quantitative HCB was dissolved in acetone to prepare HCB solution, fully stirred and mixed with the soil sample, and kept for one month. The above operations were carried out in the fume hood.

\subsubsection{Ball milling experiment}

Operation parameters of ball milling experiment, such as rotational speed (RS), material ratio (MS), ratio of different ball sizes (BDR), ratio of balls and material (R) and reaction time $(\mathrm{t})$ as well as the soil texture, organic matter and moisture content were investigated on the effect of HCB destruction. For simplicity, the mass ratio of contaminated soil to additives is denoted as MS. The mass ratio of grinding balls with different diameters is denoted as BDR. The ratio of grinding ball to total materials is denoted as $\mathrm{R}$.

The planetary ball milling was set at selected operation conditions according to experimental parameters. And the simulated soil sample, co-milling reagents and grinding balls were put into the grinding pot in a certain proportion. In order to ensure the stable operation of the machine, intermittent operation was set up, with a 15-min interval after every $1 \mathrm{~h}$.

\subsubsection{Sample treatment and analysis}

$1 \mathrm{~g}$ of grinding samples was placed in a beaker with $50 \mathrm{~mL}$ of extracting agent (VAcetone/VN-hexane=1/1), the extraction was carried out with ultrasonic device (500W ) for $15 \mathrm{~min}$ and repeated for 3 times. The collected solution was centrifuged at $3000 \mathrm{rpm}$ for $20 \mathrm{~min}$, and filtered with $0.45 \mu \mathrm{m}$ organic filter membrane. The clarified solution was concentrated by nitrogen blowing and purified by magnesium silicate purification column, and finally 
concentrated to $1 \mathrm{~mL}$.

The concentration of HCB in soil was analyzed by GCMS. The heating procedure is as follows. The temperature was set at $120^{\circ} \mathrm{C}$ holding for $2 \mathrm{~min}$ and then increased at $10{ }^{\circ} \mathrm{C} / \mathrm{min}$ to $180{ }^{\circ} \mathrm{C} \mathrm{kept}$ for $5 \mathrm{~min}$. The temperature continued to increase at $8{ }^{\circ} \mathrm{C} / \mathrm{min}$ to $240{ }^{\circ} \mathrm{C}$ holding for 1 min, and at $2{ }^{\circ} \mathrm{C} / \mathrm{min}$ to $250{ }^{\circ} \mathrm{C}$ holding for $2 \mathrm{~min}$; And then increased to $280{ }^{\circ} \mathrm{C}$ at $12{ }^{\circ} \mathrm{C} / \mathrm{min}$ holding for $2 \mathrm{~min}$. Temperature of the injection port was $250{ }^{\circ} \mathrm{C}$ with no shunt. The ion source temperature was $230{ }^{\circ} \mathrm{C}$. The scanning mode was chosen as the selective ion scanning.

\subsubsection{Characterization of grinding products}

The instant changes of grinding products with different reaction time were characterized through X-ray diffractometer (XRD), Fourier Transform Infrared Spectroscopy (FTIR), X-ray Photoelectron Spectroscopy (XPS) and Raman Spectrometer. XRD analysis was conducted at a speed of $5^{\circ} \mathrm{min}-1$ in the range of $2 \theta=10^{\circ}$ $70^{\circ}$ with $\mathrm{Cu} \mathrm{K} \alpha$ radiation (Rigaku Ultima IV, Japan) . FTIR analysis was carried out over the wave number ranging from $400 \mathrm{~cm}-1$ to $4000 \mathrm{~cm}-1$ with the $\mathrm{KBr}$ disk method (Thermo Scientific Nicolet 6700, US). XPS was conducted with $\mathrm{Al} \mathrm{K} \alpha$ radiation at energy step size of $0.05 \mathrm{eV}$ and pass energy of $30 \mathrm{eV}$ (Thermo Scientific KAlpha+, US), and the binding energy was calibrated by the surface contaminated C1s $(284.8 \mathrm{ev})$ as the standard. Raman was conducted at $514 \mathrm{~nm}$ from $50 \mathrm{~cm}-1$ to $2000 \mathrm{~cm}$ 1 (HORIBA Scientific LabRAM HR Evolution, Japan).

\section{Results and discussion}

\subsection{Effects of different operation parameters}

Albite and magnetite were chosen as the co-milling reagents to improve the damage effect of $\mathrm{HCB}$ in soil through mechanochemical method. Different operation parameters were taken into consideration: rotational speed, material ratio, ball material ratio, ratio of different ball size and milling time.

Fig. 1 displayed that the residue of $\mathrm{HCB}$ in soil decreased with the increment of rotational speed. Low degradation rate was achieved at low rotational speed. Specifically, the degradation rate was $37.9 \%$ at a speed of $300 \mathrm{rpm}$, and about $38.5 \%$ at $400 \mathrm{rpm}$. The results reflect that the energy from collision and friction between the grinding ball and materials is limited at a low running speed, which does not favor the degradation of the organic pollutants.

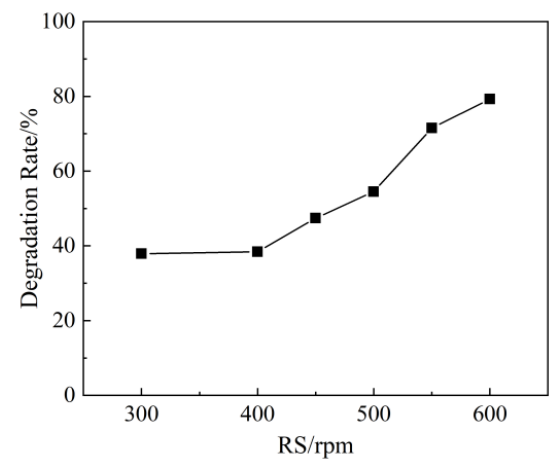

Figure 1. Effect of rotational speed on degradation rate of $\mathrm{HCB}$ in soil

$(\mathrm{t}=2 \mathrm{~h} ; \mathrm{R}=20: 1 ; \mathrm{MR}=10: 1 ; \operatorname{BDR}(\Phi 10 \mathrm{~mm}: \Phi 15 \mathrm{~mm}=1: 1))$

As the rotational speed changed from 500rpm to $550 \mathrm{rpm}$, the degradation rate was greatly enhanced to $72.5 \%$ and further increased to $79.3 \%$ when the milling speed was increased to $600 \mathrm{rpm}$. Similar results from the literatures such as nearly $100 \%$ destruction of perfluorohexane sulfonate (PFHxS) with the reagents of ferrate(VI) and zero-valent iron (ZVI), as the rotational speed was at 600rpm for $4 \mathrm{~h}$ [29] and less than $0.004 \%$ HCB left for $8 \mathrm{~h}$ operation at $550 \mathrm{rpm}$ [30] indicate that the energy input to reaction system was an important factor for reaction. Increasing rotational speed ensures increased collision frequency between the milling balls and reagents which would quickly impose on the destruction of pollutants and result in high degradation rate of HCB in soil.

Fig. 2 displays the effect of $\mathrm{MR}$ on the destruction rate of HCB. It is observed that the destruction rate of $\mathrm{HCB}$ could reach $72.2 \%$ as MR was $2: 1$ after $2 \mathrm{~h}$ milling. When the value of MR was 5:1 and 10:1, the degradation effect of HCB was slightly decreased compared with the case of MR of 2:1. It suggests that the destruction rate was decreased with increased target pollutants at the same condition. When at a MR of 15:1 and 20:1, the destruction rate was less than $60 \%$. That was easily to understand the large MR implies more target pollutants and few grinding balls that would certainly exert little energy into the reaction. Similar results that a removal rate of DDTs could reach $65.5 \%$ at the MS of 10:1 (the mass ratio of DDTs contaminated soil and $\mathrm{MgO}$ ) after $2 \mathrm{~h}$ ball milling, and it changed slightly with the increase of $\mathrm{MgO}$ addition. An increased damage effect of DDTs was achieved at a MR of 10:3 with $\mathrm{CaO}$ as the co-milling reagent [31].

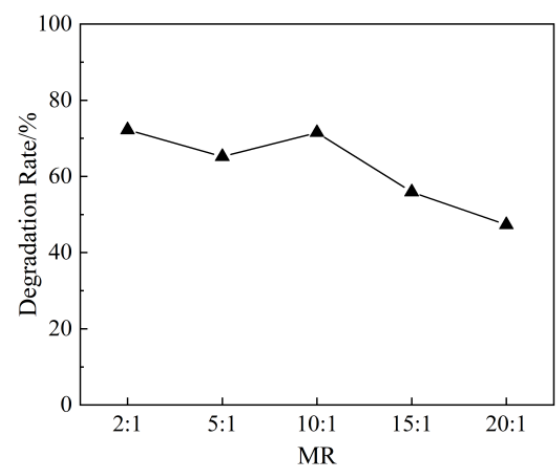

Figure 2. Effect of material ratio on degradation rate of $\mathrm{HCB}$ in soil

$(\mathrm{t}=2 \mathrm{~h} ; \mathrm{RS}=550 \mathrm{rpm} ; \mathrm{R}=20: 1 ; \operatorname{BDR}(\Phi 10 \mathrm{~mm}: \Phi 15 \mathrm{~mm}=1: 1))$ 
As the main energy input system in the experimental process, different BDR exerts an enormous function on the destruction of HCB. An in-depth study was conducted on the ball motion in planetary ball mill through the establishment of energy transfer model, and it was confirmed that the total effective impact energy and $\mathrm{R}$ are two important factors to determine the mechanochemical conversion rate of POPs [32].

Six sets of grinding ball ratio parameters were selected in the experiment, which were represented by the mass ratio of zirconia grinding balls of different sizes. Corresponding parameters conditions were shown in Table 2. Fig. 3 presents the optimal BDR to achieve relatively high $\mathrm{HCB}$ destruction rate when the size of grinding ball was medium and large that result in the welldistributed energy intensity during the operation.

Table2. Combinations of different ball diameter ratio parameters

\begin{tabular}{ccccc}
\hline Parameter & $\begin{array}{c}\Phi \\
\text { 3 } \mathbf{m m}\end{array}$ & $\Phi \mathbf{5 m m}$ & $\begin{array}{c}\Phi \\
\mathbf{1 0 m m}\end{array}$ & $\begin{array}{c}\Phi \\
\mathbf{1 5 m m}\end{array}$ \\
\hline BDR1 & $25 \mathrm{~g}$ & $50 \mathrm{~g}$ & $25 \mathrm{~g}$ & $0 \mathrm{~g}$ \\
BDR2 & $0 \mathrm{~g}$ & $0 \mathrm{~g}$ & $50 \mathrm{~g}$ & $50 \mathrm{~g}$ \\
BDR3 & $0 \mathrm{~g}$ & $0 \mathrm{~g}$ & $0 \mathrm{~g}$ & $100 \mathrm{~g}$ \\
BDR4 & $0 \mathrm{~g}$ & $0 \mathrm{~g}$ & $100 \mathrm{~g}$ & $0 \mathrm{~g}$ \\
BDR5 & $0 \mathrm{~g}$ & $33.3 \mathrm{~g}$ & $33.3 \mathrm{~g}$ & $33.3 \mathrm{~g}$ \\
BDR6 & $0 \mathrm{~g}$ & $25 \mathrm{~g}$ & $50 \mathrm{~g}$ & $25 \mathrm{~g}$ \\
\hline
\end{tabular}

The worst destruction effect with BDR of 1, manifested that the desired effect of large grinding ball was better than that of small grinding ball. Due to the high quality of grinding balls, the force exerted on materials increased correspondingly, which accelerated the degradation of pollutants. What's more, the grinding ball with large diameter can easily engender milling blind area during the reaction process, which meant that the combination of large and small grinding balls can ensure the applied density and reaction area of mechanical force at the same time. It was probed that different grinding ball size ratio could significantly affect the destruction of DDTs in soil with the reagent of $\mathrm{CaO}$, and the effect of applying solely large ball was worst [33]. The ratio of grinding balls with different sizes impacts the collision density and frequency, which can be proved by that the results obtained under the same value of $\mathrm{R}$.

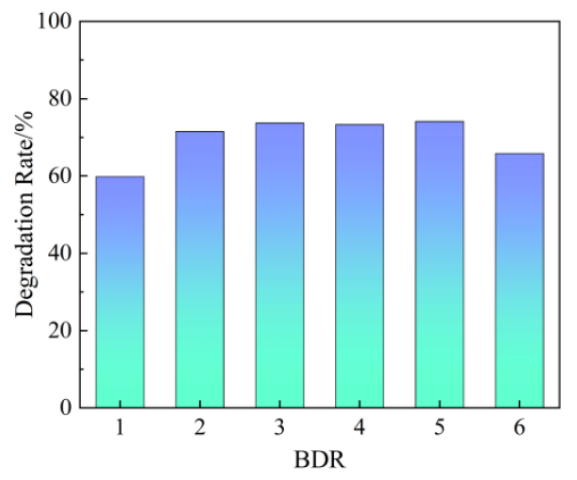

Figure 3. Effect of ball ratio parameters on degradation rate of HCB in soil
The contact efficiency between materials and milling ball was affected by ball material ratio. An appropriate ratio could achieve the efficient damage of pollutants as well as improve the capacity of single contaminated soil treatment with the appropriate filling ensured.

It was indicated in Fig. 4 that the increasing tendency of HCB degradation rate was gentle with $\mathrm{R}$. The damage rate of $\mathrm{HCB}$ was $81.1 \%$ as $\mathrm{R}$ was $30: 1$, and a rapid increase in degradation rate of $\mathrm{HCB}$ was achieved as $\mathrm{R}$ was changed from $15: 1$ to $20: 1$. When $R$ was $10: 1$ and $15: 1$, the damage of HCB in soil was less than $70 \%$. It was demonstrated that the destruction efficiency of HCB was significantly improved with the increase of $\mathrm{R}$. The degradation rate of $\mathrm{HCB}$ increased from $26.7 \%$ to $86.3 \%$ as $\mathrm{R}$ increased from $10: 1$ to $20: 1$ [34]. While $\mathrm{R}$ reaches a certain value, the effective counteraction force between grinding balls increases, and the energy generated by collision is beneficial to the structural damage of pollutants.

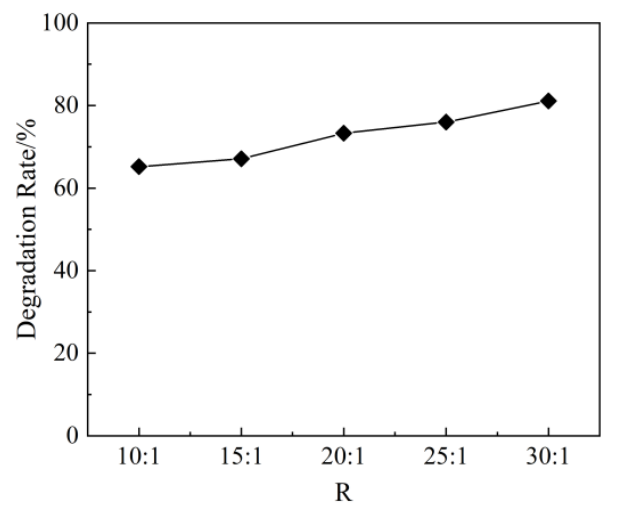

Figure 4. Effect of ball material ratio on degradation rate of $\mathrm{HCB}$ in soil

$(\mathrm{t}=2 \mathrm{~h} ; \mathrm{RS}=550 \mathrm{rpm} ; \mathrm{MR}=10: 1 ; \operatorname{BDR}(\Phi 10 \mathrm{~mm}: \Phi 15 \mathrm{~mm}=1: 1))$

Milling time is directly associated with the extent of mechanochemical remediation of contaminated soil. The prolonged milling time would give rise to excessive power consumption and impose a burden to equipment operation and maintenance. In order to determine the suitable time for HCB contaminated soil treatment, six working conditions were set up, including $1 \mathrm{~h}, 2 \mathrm{~h}, 3 \mathrm{~h}, 4 \mathrm{~h}, 5 \mathrm{~h}$ and $6 \mathrm{~h}$.

With the extension of milling time, the removal rate of HCB in contaminated soil increased, as shown in Fig. 5. The destruction rate of $\mathrm{HCB}$ was rapidly enhanced from $43.8 \%$ to $87.67 \%$ as t was increased from $1 \mathrm{~h}$ to $4 \mathrm{~h}$. As the milling time continued to extend, the destruction rate increased gently. When $t$ was $6 \mathrm{~h}$, the damage rate of $\mathrm{HCB}$ could reach $92.52 \%$. With the continuous accumulation of mechanical collision, the complex chemical reactions occurred between $\mathrm{HCB}$ and co-milling reagents. Considering the treatment effect and economic benefits, the suitable milling time would be $5 \mathrm{~h}$, while the destruction rate of $\mathrm{HCB}$ is more than $90 \%$, a more economical and efficient choice, slightly lower than the destruction effect of $6 \mathrm{~h}$. 


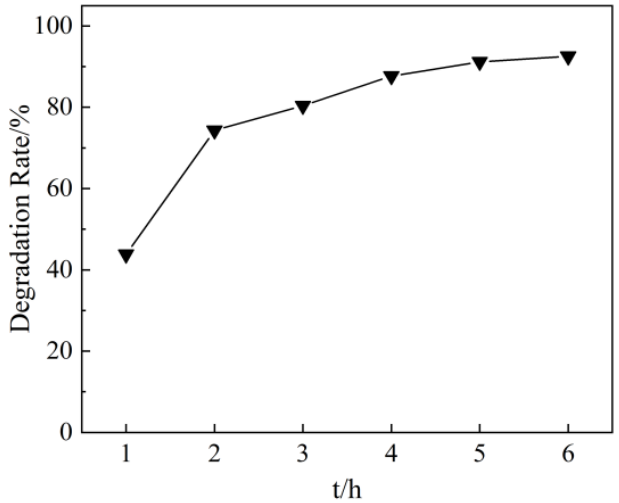

Figure 5. Effect of milling time on degradation rate of HCB in soil

(RS=550rpm; MR=10:1; BDR( $\Phi 10 \mathrm{~mm}: \Phi 15 \mathrm{~mm}=1: 1) ; \mathrm{R}=20: 1)$

\subsection{Effects of soil texture}

The adhesion force between pollutants and soil was closely related to soil quality, and the interception of pollutants were relevant to the type of soil, which possesses different adsorption capacity. Li et al. probed into the relationship between soil properties and pollutants, such as volatile organic compounds (VOCs) and total petroleum hydrocarbons (TPH), at specific contaminated site. It was manifested that the TPH content was higher in the surface plain fill, while the VOCs was low. In the clay layer, a large amount of TPH and VOCs were adsorbed on the top of the soil layer [35]. Organic pollutants had a strong binding force with clay, which hindered the destruction of pollutants.

Different classifications of HCB contaminated soils, including sand, loam and clay, were selected for the study. Quartz sand, garden soil and montmorillonite powder were utilized as sand source, loam source and clay source respectively. The concentration of $\mathrm{HCB}$ in simulated contaminated soil was $50 \mathrm{mg} / \mathrm{kg}$.

It was shown in Fig. 6 that the degradation effect of HCB in contaminated sand was the best, in which the residue components was nearly non-detectable, followed by the contaminated loam, and the destruction extent of contaminated clay was the worst. The quartz sand was lack of organic matter and had the worst adsorption capacity to pollutants. The garden soil had suitable content of nutrient and organic matter, which was closely combined with pollutants and had little impact on pollutant destruction. The clay had small particle size and developed pores, which provided abundant retention sites for pollutants. Van der Waals force and hydrogen bond interaction made the organic and inorganic contaminants bounded to particles tightly [36]. Therefore, the clay was most closely combined with pollutants, resulting in poor ball milling effect, and its HCB degradation rate could only reach $31.4 \%$.

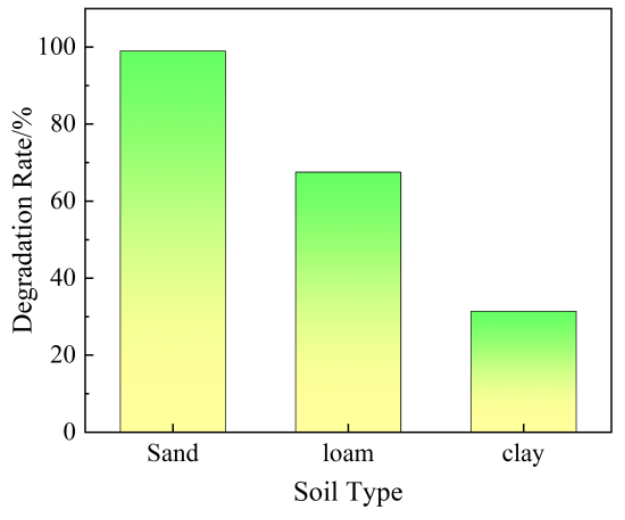

Figure 6. Effect of soil type on degradation of HCB in soil $(\mathrm{t}=4 \mathrm{~h} ; \mathrm{RS}=550 \mathrm{rpm} ; \mathrm{R}=20: 1 ; \mathrm{MR}=10: 1$; $\operatorname{BDR}(\Phi 10 \mathrm{~mm}: \Phi 15 \mathrm{~mm}=1: 1))$

Soil aggregates and organic matter affect the adsorption and migration of organic pollutants in the soil [37]. The adsorption of pollutants by organic matter was one of the factors affecting the mechanochemical degradation of contaminants. In order to probe into the effect of organic matter content on the degradation of $\mathrm{HCB}$, four groups of ball milling experiments of contaminated soil with different contents of organic matter were set up. Humic acid was added into the soil as exogenous organic matter with the addition of $2 \mathrm{wt} . \%, 5 \mathrm{wt} . \%, 10 \mathrm{wt} . \%$ and $15 \mathrm{wt} . \%$, respectively.

Due to the influence of aging time, soil texture and moisture, the ability of soil to absorb and transform exogenous organic matter is limited. The organic matter analysis of aging soil samples was carried out as shown in Table 3. With the increase of exogenous nutrient, the content of organic matter in soil increased from $4.98 \%$ to $10.6 \%$, which effectively improved the nutrient structure of soil.

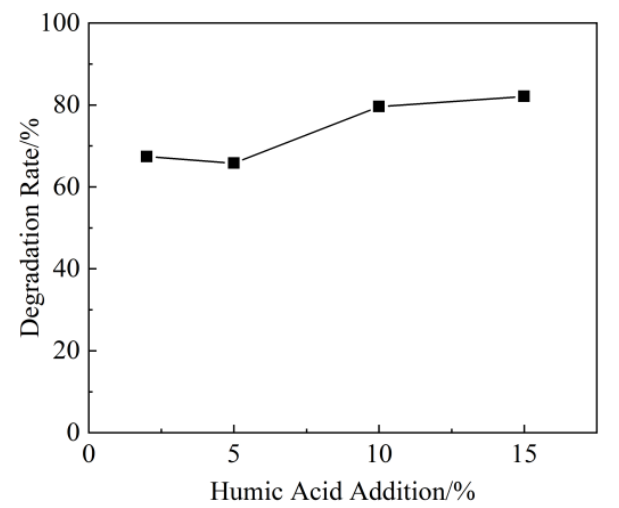

Figure 7. Effect of organic matter content on degradation rate of HCB in soil

$(\mathrm{t}=4 \mathrm{~h} ; \mathrm{RS}=550 \mathrm{rpm} ; \mathrm{R}=20: 1 ; \mathrm{MR}=10: 1$; $\operatorname{BDR}(\Phi 10 \mathrm{~mm}: \Phi 15 \mathrm{~mm}=1: 1))$

Fig. 7 displayed that with the increment of humic acid in soil, the destruction of HCB in soil initially decreased, then followed by an increase. The degradation rate of $\mathrm{HCB}$ was $82.1 \%$ when humic acid addition was $15 \mathrm{wt} . \%$. As the humic acid addition was low, the binding ability of soil with HCB was higher than that of soil without humic acid addition, which resulted in the decreased degradation rate of HCB during ball milling. Li et al. clarified that the 
adsorption capacity of bisphenol A in soil increased with the increment of soil organic matter content [37]. The contaminants accumulated due to the adsorption of humic acid as the increase of humic acid addition, which concentrated the pollutants in soil, and improved the degradation effect of HCB. The organic matter in soil in China is mostly $1 w t . \%-5 w t . \%$, and the damage rate of pollutants is less than $70 \%$ without exogenous organic matter. Therefore, reasonable application of exogenous nutrients can not only improve the soil nutritional status, but also improve the degradation efficiency of POPs contaminated soil.

Table 3. Distribution of organic matter content in soil samples

\begin{tabular}{ccccc}
\hline Humic Acid Addition/ \% & 2 & 5 & 10 & 15 \\
\hline Organic Matter/ \% & 4.98 & 7.62 & 9.46 & 10.60 \\
\hline
\end{tabular}

The effect of moisture content in contaminated soil on the HCB degradation rate is an important factor to balance the pretreatment cost. Drying time of soil and treatment cost would be controlled effectively as the influence of moisture was determined. Four experimental groups of 0wt.\%, 3wt.\%, 5wt.\%, 10wt.\% were set up to explore the influence of moisture content on HCB degradation. The experiment results were shown in Fig. 8.

$71.5 \%$ of HCB damage rate was achieved when the polluted soil was completely dried. Great decrease in degradation rate was seen as the soil moisture increased from $0 \%$ to $3 \%$, which reflected the hindrance of water to destroy pollutants by mechanochemical method. With the moisture content further increased to $5 \mathrm{wt} . \%$, not much change in the destruction of $\mathrm{HCB}$ rate of $65 \%$, while it decreased to less than $60 \%$ as the moisture increased to 10wt.\%.

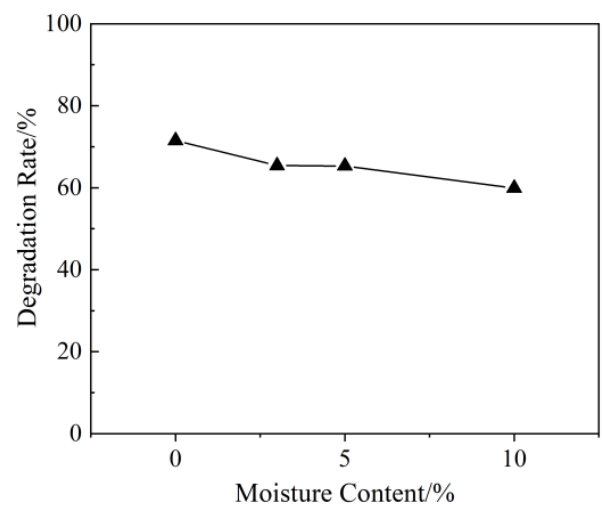

Figure 8. Effect of moisture content on degradation rate of HCB in soil

$(\mathrm{t}=4 \mathrm{~h} ; \mathrm{RS}=550 \mathrm{rpm} ; \mathrm{R}=20: 1 ; \mathrm{MR}=10: 1$; $\operatorname{BDR}(\Phi 10 \mathrm{~mm}: \Phi 15 \mathrm{~mm}=1: 1))$

The planetary ball mill with zirconia pots and balls was used as the reaction system to destroy POPs in soil. The resistance of the ball movement raised with high content of moisture. Continuous hits led to the adhesion of soil to grinding balls and tank walls, resulted in uneven impact frequency and density of pollutants, which was not beneficial to the damage of HCB in soil. Thus, in order to achieve high degradation rate, it is necessary to extend the reaction time, which increase the power consumption and equipment operation burden. Therefore, the moisture content of polluted soil should be less than $5 \mathrm{wt} . \%$ to ensure the degradation efficiency with low cost in the process of drying.

\subsection{Characteristics of milling products}

In order to clarify the mechanochemical effect of albite and $\mathrm{Fe} 3 \mathrm{O} 4$ on $\mathrm{HCB}$ in soil, FTIR was conducted on the products of different milling time to identify the group transformation during ball milling [38].

As shown in Fig. 9, a sharp moderate intensity adsorption peak at $3617.8 \mathrm{~cm}-1$ was detected for the original samples $(0 \mathrm{~h})$ which was caused by $-\mathrm{OH}$ stretching vibration. The absorption intensity decreased gradually with the increase of milling time, indicating that $-\mathrm{OH}$ has participated in the reaction. The peaks at $3021.9 \mathrm{~cm}-1$ and $2897.5 \mathrm{~cm}-1$ were $=\mathrm{C}-\mathrm{H}$ stretching vibration and saturated $-\mathrm{C}-\mathrm{H}$ antisymmetric stretching vibration, respectively and disappeared during the reaction.

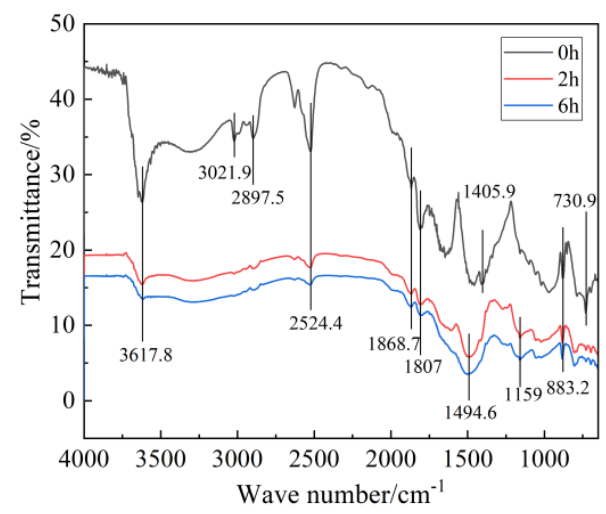

Figure 9. FTIR spectra of products at different reaction time (RS=500rpm; R=20:1; MR=1:1; BDR(Ф10mm:Ф15mm=1:1))

The peak at $730.9 \mathrm{~cm}-1$ originated from the $\mathrm{C}-\mathrm{Cl}$ stretching vibration of $\mathrm{HCB}$ molecule, and the absorption peak was weakened and disappeared after ball milling, indicating $\mathrm{HCB}$ molecule has been destroyed. The enhancement peak of $1868.7 \mathrm{~cm}-1$ was carbonyl $-\mathrm{C}=\mathrm{O}$ stretching vibration, from the effect of phenoxy. The new peaks at $1494.6 \mathrm{~cm}-1,1159 \mathrm{~cm}-1$ and $883.2 \mathrm{~cm}-1$ were $\mathrm{C}=\mathrm{C}$ stretching vibration in aromatic ring, stretching vibration of $\mathrm{C}-\mathrm{O}$ and wagging vibration of $=\mathrm{CH} 2$, respectively. The three new absorption peaks were mainly from the intermediate products generated after dechlorination of HCB $[37,23,24]$.

The raw materials had three sharp Raman peaks at $177.1 \mathrm{~cm}-1,300.3 \mathrm{~cm}-1$ and $1097.9 \mathrm{~cm}-1$ as shown in Fig. 10. After $2 \mathrm{~h}$ reaction, the three characteristic peaks became weaker and a new moderate peak engendered at $1354.8 \mathrm{~cm}-1$. After $6 \mathrm{~h}$ reaction, the peaks at $177.1 \mathrm{~cm}-1$ and $197.9 \mathrm{~cm}-1$ faded away, and a new peak at $1578.9 \mathrm{~cm}-1$ emerged, which indicated that the pollutants was damaged gradually and new products appeared. According to Raman characteristic peaks of carbon crystal, D band and $\mathrm{G}$ band, are located at approximate $1300 \mathrm{~cm}-1$ and $1580 \mathrm{~cm}-1$ respectively. D band represents lattice defect of carbon, reflecting the disorder of crystal structure, and $G$ band represents the first-order scattering E2g vibration 
mode, which is applied to characterize the sp2 bond structure of carbon.

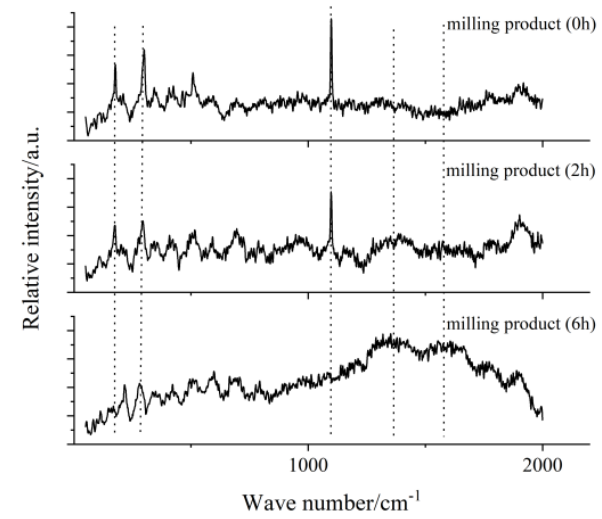

Figure 10. Raman spectra of different milling products $(\mathrm{RS}=500 \mathrm{rpm} ; \mathrm{R}=20: 1 ; \mathrm{MR}=1: 1 ; \operatorname{BDR}(\Phi 10 \mathrm{~mm}: \Phi 15 \mathrm{~mm}=1: 1))$

Upon the previous studies, the peak at $1354.8 \mathrm{~cm}-1$ belongs to the defect and disorder of carbon structure, specifically the amorphous carbon, and the response peak at $1578.9 \mathrm{~cm}-1$ belongs to the graphite. Raman spectrum clearly showed that carbonization process occurred in the process of mechanochemical reaction [30,24,39].

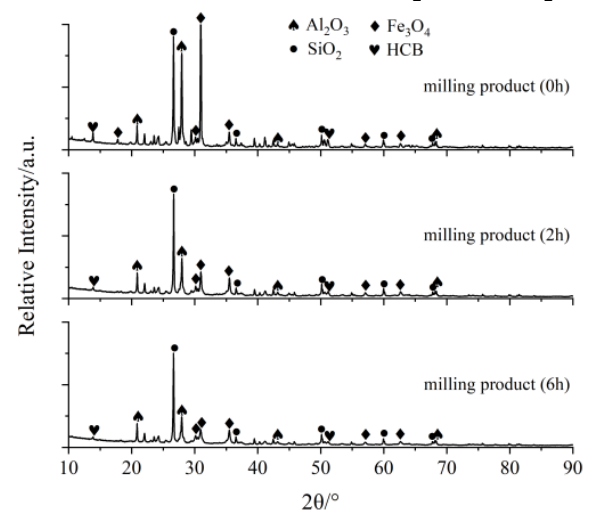

Figure 11. XRD patterns of the milling products at different reaction time

XRD was applied to verify the crystalline forms of milling mixtures. It was depicted in Fig. 11 that the peak of HCB in soil samples were largely decreased after $6 \mathrm{~h}$ milling, as a result of destruction caused by mechanical stress.

The peak intensity of other inorganic substances, i.e., $\mathrm{Fe} 3 \mathrm{O} 4$ and $\mathrm{Al} 2 \mathrm{O} 3$, was obviously weakened, and the peaks became broad and weak with the grinding aggravation. It was manifested that the crystallinity decreased and the ball milling mixture became amorphous. The changes happened in structure of mixtures, made the damage reaction of $\mathrm{HCB}$ in soil possible.

In order to clarify the effect of $\mathrm{Fe} 3 \mathrm{O} 4$, the solid residues were exploited to detect the chemical environment of Fe 2p by XPS. As shown in Fig. 12, for the raw mixture, two typical peaks were measured at $711.0 \mathrm{eV}$ and $724.5 \mathrm{eV}$, which were attributed to $\mathrm{Fe} 2 \mathrm{p} 3 / 2$ and $\mathrm{Fe}$ $2 \mathrm{p} 1 / 2$, respectively. Peak differentiating and imitating analysis was detected at the peak of Fe $2 \mathrm{p} 3 / 2$, and two fitting peaks were achieved at $711.5 \mathrm{eV}$ and $710.4 \mathrm{eV}$ [40]. The former stood for $\mathrm{Fe} 3+$, while $\mathrm{Fe} 2+$ was represented by the latter. The ratio of peak area between $\mathrm{Fe} 3+$ and $\mathrm{Fe} 2+$ was about $2: 1$, which was consistent with that the theoretical electronic composition of $\mathrm{Fe} 3 \mathrm{O} 4$. The results showed that the ratio of peak area between the two kinds of electron increased after $6 \mathrm{~h}$ ball milling as shown in Fig. 13.

The following reactions must have occurred:

$$
\begin{aligned}
& \mathrm{Fe} 2+-\mathrm{e}=\mathrm{Fe} 3+ \\
& \mathrm{HCB}+\mathrm{e}-=\mathrm{HCB}-
\end{aligned}
$$

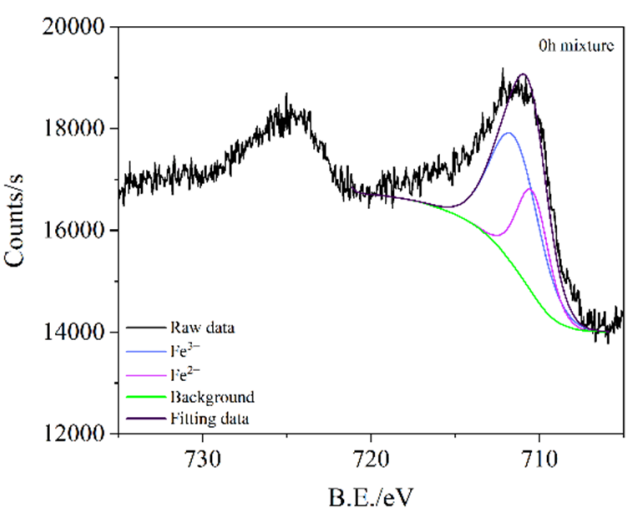

Figure 12. XPS spectra (Fe $2 p)$ of raw materials

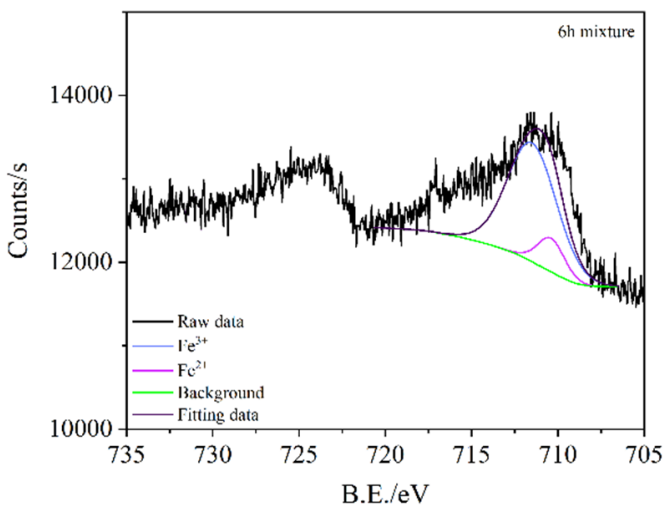

Figure 13. XPS spectra ( $\mathrm{Fe} 2 \mathrm{p})$ of milling mixture at $6 \mathrm{~h}$

The internal electron transformation between $\mathrm{Fe} 2+$ and $\mathrm{Fe} 3+$ in $\mathrm{Fe} 3 \mathrm{O} 4$ brought in electrons for the reaction system, which promoted the generation of $\mathrm{HCB}$ anion, as shown in Equation 2 [23]. The process of receiving electron of $\mathrm{HCB}$ is an endothermic reaction, which requires certain amounts of energy to stimulate it. What's more, the electronegativity of HCB- was strengthened by extra electrons in the molecule, which caused an increased mean length of $\mathrm{C}-\mathrm{Cl}$, about $0.02 \AA$ higher than that of $\mathrm{HCB}$, and thus weakened the $\mathrm{C}-\mathrm{Cl}$ [23]. A series of dissolved reactions would happen during the destruction of $\mathrm{HCB}$ by giving rise to stable chlorine.

\section{Conclusion}

The feasibility of destroy HCB in soil with the mechanochemistry method was studied. The parameters such as rotational speed (RS), material ratio (MS), milling time $(\mathrm{t})$, ratio of ball size (BDR), classifications of soil, moisture and organic matter in soil, etc., were investigated 
on the influence of $\mathrm{HCB}$ destruction rate in contaminated soil. It was manifested that degradation rate of $\mathrm{HCB}$ could reach $92.5 \%$ after $6 \mathrm{~h}$ milling with the BDR of $2, \mathrm{RS}$ of $550 \mathrm{rpm}, \mathrm{MS}$ of 10:1 and R of 10:1, while the enough energy from collision and friction was achieved.

The classifications of soil and content of organic matter present the significant effect on HCB destruction rate in soil because of the difference in absorption from different organic components existing in soil, while the remediation of HCB contaminated sand with few organic matters was complete, compared with loam and clay. Soil moisture exerted a certain blocking effect on the mechanochemical reaction, and resulted in increased movement resistance for grinding balls, leading to an uneven collision density and frequency.

Natural mineral assemblage had significant effect on the damage of HCB in soil. The specific composition and structure of Albite combined with the input internal electron transformed from the magnetite during the reaction, were greatly beneficial to the destruction of POPs in contaminated soil. The work presents an environmental friendly and efficiently method for POPs contaminated soil remediation with few impact on soil texture.

\section{References}

1. S. Q. Chen, J. Li, X. Y. Huang, Y. G. Wang. Environmentally friendly flame retardants and Stockholm Convention. China International Adhesive Technology Conference 2016 (Xian), pp.729-735.

2. T. Núñez-Rocha, I. Martínez-Zarzoso. Are international environmental policies effective? The case of the Rotterdam and the Stockholm Conventions. Econ. Model., 81 (2019), pp. 480-502.

3. A. A. Jennings, Z. J. Li. Residential surface soil guidance applied worldwide to the pesticides added to the Stockholm Convention in 2009 and 2011, J. Environ. Manage., 160 (2015), pp. 226-240.

4. L. Y. Liu, W. L. Ma, H. L. Jia, Z. F. Zhang, W. W. Song, Y. F. Li. Research on persistent organic pollutants in China on a national scale: 10 years after the enforcement of the Stockholm Convention, Environ. Pollut., 217 (2016), pp. 70-81.

5. F. Chen, Z. B. Luo, G. J. Liu, Y. J. Yang, S. L. Zhang, J. Ma. Remediation of electronic waste polluted soil using a combination of persulfate oxidation and chemical washing, Environ. Manage., 204 (2017), pp. 170-178.

6. Venny, S. Y. Gan, H. Kiat Ng. Current status and prospects of Fenton oxidation for the decontamination of persistent organic pollutants (POPs) in soils. Chem. Eng. J., 213 (2012), pp. 295317.

7. Y. R. Li, H. P. Zhao, L. Z. Zhu. Remediation of soil contaminated with organic compounds by nanoscale zero-valent iron: A review, Sci. Total. Environ., (2020).

8. E. Morillo, J. Villaverde. Advanced technologies for the remediation of pesticide-contaminated soils, Sci. Total. Environ., 586 (2017), pp. 576-597.

9. B. H. Sun, Q. Q. Li, M. H. Zheng, G. J. Su, S. J. Lin, M. G. Wu, C. Q. Li, Q. L. Wang, Y. M. Tao, L. W. Dai, Y. Qin, B. Meng. Recent advances in the removal of persistent organic pollutants (POPs) using multifunctional materials: a review, Environ. Pollut., 265 (2020).

10. V. H. Nguyen, S. W. Meejoo Smith, K. Wantala, P. Kajitvichyanukul. Photocatalytic remediation of persistent organic pollutants (POPs): A review, Arab. J. Chem, 13 (2020), pp. 8309-8337,

11. N. S. Kozhevnikova, T. I. Gorbunova, A. S. Vorokh, M. G. Pervova, A. Y. Zapevalov, V. I. Saloutin, O. N. Chupakhin. Nanocrystalline $\mathrm{TiO}_{2}$ doped by small amount of pre-synthesized colloidal CdS nanoparticles for photocatalytic degradation of 1,2,4-trichlorobenzene, Sustain. Chem. Pharm., 11 (2019), pp. 1-11.

12. T. D. Pham, R. A. Shrestha, J. Virkutyte, M. Sillanpää. Combined ultrasonication and electrokinetic remediation for persistent organic removal from contaminated kaolin, Electrochi. Acta, 54 (2009), pp. 1403-1407.

13. A. Oonnittan, P. Isosaari, M. Sillanpää. Oxidant availability in soil and its effect on HCB removal during electrokinetic Fenton process, Sep. Purif. Technol, 76 (2010), pp.146-150.

14. X. J. Meng, K. Zhu, Y. F. Jiang, Z. R. Nan. Experimental study on electrokinetic remediation of phenol contaminated soil. J. Environ. Sci. Manage, 35 (2010), pp.70-74.

15. S. S. Liu, Z. L. Chen, B. Liu, D. Ma, Y. X. Xu, X. C. Peng. Field demonstration of soil vapor extraction on diesel fuel contaminated site, J. Soil Water Conserv., 27 (2013), pp.172-175,181.

16. R. J. Davis, H. M. Liljestrand, L. E. Katz. Evidence for multiple removal pathways in low-temperature $\left(200-400^{\circ} \mathrm{C}\right)$ thermal treatment of pentachlorophenol-laden soils, J. Hazardous. Mater., 400 (2020).

17. H. F. Liu, X. S. Meng, W. Zhao. Case study on soil remediation effect of in situ gas thermal desorption under different sampling temperatures. Energy Environ. Prot., 34 (2020), pp.51-54.

18. F. Z. Li, Y. P. Zhang, S. Wang, G. B. Li, X. P. Yue, D. X. Zhong, C. H. Chen, K. Shen. Insight into ex-situ thermal desorption of soils contaminated with petroleum via carbon number-based fraction approach, Chem. Eng. J., 385 (2020).

19. J. Liu, H. Zhang, Z. T. Yao, X. D. Li, J. H. Tang. Thermal desorption of PCBs contaminated soil with calcium hydroxide in a rotary kiln, Chemosphere, 220 (2019), PP.1041-1046.

20. G. Anitescu, L.L. Tavlarides. Supercritical extraction of contaminants from soils and sediments, J. Supercrit. Fluids, 38 (2006), pp.167-180.

21. R. Medina, A. J. Fernández-González, F. M. García- 
Rodríguez, P. J. Villadas, J. A. Rosso, M. Fernández-López, M. T. Del Panno. Exploring the effect of composting technologies on the recovery of hydrocarbon contaminated soil post chemical oxidative treatment, Appl. Soil Ecol., 150 (2020).

22. X. Y. Ren, G. M. Zeng, L. Tang, J. J. Wang, J. Wan, J. J. Wang, Y. C. Deng, Y. N. Liu, B. Peng. The potential impact on the biodegradation of organic pollutants from composting technology for soil remediation, Waste Manage., 72 (2018), pp. 138-149.

23. S. S. Deng, S. G. Kang, N. N. Feng, J. X. Zhu, B. Yu. Mechanochemical mechanism of rapid dechlorination of Hexachlorobenzene, J. Hazard. Mater., 333 (2017), pp.116-127.

24. Y. J. Li, Q. N. Liu, W. F. Li, Y. Z. Lu, H. Meng. Efficient destruction of hexachlorobenzene by calcium carbide through mechanochemical reaction in a planetary ball mill. Chemosphere, 166 (2017), pp.275-280.

25. S. Rowlands, A. Hall, P. G. McCormick, R. Street, R. J. Hart, G. F. Ebell, P. Donecker. Destruction of toxic materials, Nature, 367 (1994), 223.

26. Q. J. Mao, S. Y. Lu, Y. L. Wei, X. D. Li, J. H. Yan. Treatment of polychlorinated contaminated soil by horizontal ball milling. Environ. Chem., 35 (2016), pp. 607-614.

27. G. Cagnetta, J. Robertson, J. Huang, K. L. Zhang, G. Yu. Mechanochemical destruction of halogenated organic pollutants: A critical review. J. Hazard. Mater., 313 (2016), pp.85-102.

28. Y. Tanaka, Q Zhang, F. Saito, T. Ikoma, S. Terokubota. Dependence of mechanochemically induced decomposition of mono-chlorobiphenyl on the occurrence of radicals. Chemosphere, 60 (2005), pp.939-943.

29. S. S. Deng, Y. X. Bao, G. Cagnetta, J. Huang, G. Yu. Mechanochemical degradation of perfluorohexane sulfonate: Synergistic effect of ferrate(VI) and zerovalent iron, Environ. Pollut., 264 (2020)

30. W. Zhang, Y. F. Yu, J. Huang, S. B. Deng, G. Yu.
Mechanochemical degradation of hexachlorobenzene by iron and quartz sand, Forum on persistent organic pollutants 2011 and the sixth national symposium on persistent organic pollutants, 2011(Heilongjiang)

31. H. B. Li. Mechanochemical treatment of soil DDT based on calcium oxide and its mechanism. Tianjin: Tianjin University (2015), pp. 24-25, 26-28.

32. Z. L. Chen, S. Y. Lu, Q. J. Mao, B. K. Alfons, Y. T. Wang, J. H. Yan. Energy transfer and kinetics in mechanochemistry. Environ. Sci. Pollut. Res., 24 (2017), pp.24562-24571.

33. P. Wu. Preliminary study on mechanochemical treatment of high concentration DDT contaminated soil. Tianjin: Tianjin University. (2014), pp.68-72.

34. Y. F. Ren, S. G. Kang, J. X. Zhu. Mechanochemical degradation of hexachlorobenzene using $\mathrm{Mg} / \mathrm{Al}_{2} \mathrm{O}_{3}$ as additive, J. Mater. Cycles. Waste Manag., 17 (2015), pp. 607-615.

35. L. Y. Li, Z. J. Luo, H. Peng. Vertical distribution of petroleum pollutants in cohesive soil. Safe. Environ. Eng., 21 (2014), pp. 57-62.

36. G. X. Fan, X. T. Liu, X. W. Li, C. Y. Lin, M. C. He, W. Ouyang. Mechanochemical treatment with $\mathrm{CaO}$ activated PDS of HCB contaminated soils, Chemosphere, 257 (2020)

37. R. J. Li, L. Q. Yang, J. Zhuang, Y. N. Shi, X. J. Chen. Effects of organic matter and aggregates on migration behavior of bisphenol A. J. Ecol., (2020)

38. M. H. Zhu, P. Hu. Instrumental analysis. Beijing: Higher Education Press, (2008), pp.290-308.

39. W. Zhang, H. Z. Wang, J. Huang, M. Yu, F. Wang, L. B. Zhou, G. Yu. Acceleration and mechanistic studies of the mechanochemical dechlorination of HCB with iron powder and quartz sand, Chem. Eng. J., 239 (2014), pp. 185-191.

40. D. X. Zhao. Preparation, characterization and magnetorheological behavior of $\mathrm{Fe}_{3} \mathrm{O}_{4}$ particles with different morphologies. Heibei University of Engineering. (2019), pp. 32-33. 